\title{
ARTICLE
}

\section{Photoinitiated charge separation in a hybrid titanium dioxide metalloporphyrin peptide material}

\author{
H. Christopher Fry ${ }^{1}$, Yuzi Liu', Nada M. Dimitrijevic ${ }^{1} \&$ Tijana Rajh ${ }^{1}$
}

In natural systems, electron flow is mediated by proteins that spatially organize donor and acceptor molecules with great precision. Achieving this guided, directional flow of information is a desirable feature in photovoltaic media. Here, we design self-assembled peptide materials that organize multiple electronic components capable of performing photoinduced charge separation. Two peptides, $\mathrm{c}^{16}-\mathrm{AHL}_{3} \mathrm{~K}_{3}-\mathrm{CO}_{2} \mathrm{H}$ and $\mathrm{c} 16-\mathrm{AHL}_{3} \mathrm{~K}_{9}-\mathrm{CO}_{2} \mathrm{H}$, self-assemble into fibres and provide a scaffold capable of binding a metalloporphyrin via histidine axial ligation and mineralize titanium dioxide $\left(\mathrm{TiO}_{2}\right)$ on the lysine-rich surface of the resulting fibrous structures. Electron paramagnetic resonance studies of this self-assembled material under continuous light excitation demonstrate charge separation induced by excitation of the metalloporphyrin and mediated by the peptide assembly structure. This approach to dye-sensitized semiconducting materials offers a means to spatially control the dye molecule with respect to the semiconducting material through careful, strategic peptide design.

\footnotetext{
${ }^{1}$ Argonne National Laboratory, Center for Nanoscale Materials, 9700 South Cass Avenue, Argonne, Illinois 60439, USA. Correspondence and requests for materials should be addressed to H.C.F. (email: hfry@anl.gov).
} 
T he flow of energy and information in natural systems is governed by carefully positioned donor and acceptor molecules ${ }^{1}$. The electrons flow through bond, through space or via a hopping mechanism. Developing a functional material that controls the flow of electrons based on these principles of nature is prevalent but often implementation of structural elements is lost. The conformation and relative spatial separation between the two components dictates the efficiency and the rate at which electrons are transferred. The protein serves as the architectural scaffold for organizing the molecules which, in turn, provides its ultimate function. For example, the wellknown intensely green coloured molecule chlorophyll is an excellent light-harvesting molecule but really offers very little utility when functioning alone. When the protein light-harvesting complex II found in purple bacteria binds and organizes the chromophore, the required light-harvesting properties for initiating the transformation of light into food are achieved ${ }^{2,3}$. This is but one example of nature's achievement in employing proteins to govern the flow of electrons.

The elegance of photoinduced charge separation, as found in nature, inspired the design for dye-sensitized solar cells (DSCs $^{4,5}$. In a DSC, a porous network of crystalline titanium(IV) dioxide $\left(\mathrm{TiO}_{2}\right)$ nanoparticles, is sensitized by the random adsorption or coordination of a dye molecule to the surface of the semiconducting metal oxide particles. On illumination, the dye molecule injects an electron into the conduction band of $\mathrm{TiO}_{2}$ resulting in efficient charge separation. To date, the record conversion efficiency was achieved with a zinc metalloporphyrin dye, $\eta_{\text {eff }}=12.7 \%$ (ref. 6). Significant loss in efficiency is possibly due to the multiple electron and energy transfer pathways after the initial photoexcitation process. Although it is difficult to compare the efficiencies of photovoltaic devices to natural photosynthetic systems where the overall efficiency is often cited as an optimistic 3\%, much of the energy loss that occurs is nature's intent for reasons of regeneration, environment and many other factors that are problems relevant to systems biology ${ }^{7-9}$. Nature is therefore purposely directing its electrons through guided pathways utilizing the harvested light in multiple processes. Therefore, developing a material that can control the direction of electron flow based on natural principles will provide necessary insight towards the importance of structural arrangement in a photovoltaic medium.

Here, we take inspiration from the same natural source that resulted in DSCs, light-harvesting systems ${ }^{2,3,10}$. Much of the current work for varying the distance and orientation of the dye molecule relative to the surface of the semiconducting material relies extensively on the synthesis of new dye molecules ${ }^{11-14}$. We have developed an alternative, strategic approach to organizing the dye molecule and the semiconducting material by employing a self-assembled peptide amphiphile as the structural template. The design has been shown to bind and organize a variety of metalloporphyrins on extensive length scales in the form of fibrillar structures ${ }^{15}$. The resulting structure produces a surface rich in lysine residues, which have been shown to induce $\mathrm{TiO}_{2}$ mineralization by both unassembled and assembled peptide systems in good yield ${ }^{16-21}$. The final material is a peptide fibre that internally binds a metalloporphyrin and externally mineralizes $\mathrm{TiO}_{2}$. As the dye molecule is not attached to the semiconducting particle through a covalent bridge, the pathway for electron transfer occurs either through space or the peptide. The present work highlights our ability to generate a complex material from simple starting precursors that is capable of noncovalently organizing donor and acceptor moieties such that the material yields a charge-separated state upon illumination with visible light.

\section{Results}

Design. The use of novel architectures in photovoltaic and photocatalytic systems stems from the influence of nature that employs guided pathways for electron transfer. The ultimate goal is to have a simple design guided by natural principles that yields a complex structure that dictates donor and acceptor organization. Here, we combine a peptide, a synthetic metalloporphyrin (5,15-diphenylporphyrin)Zinc, (DPP)Zn, and titania precursor, Fig. 1, that self-assemble into an architecture capable of photoinduced charge transfer, Fig. 2. The peptides were designed as described before ${ }^{15}$. Briefly, an aliphatic c16 tail was incorporated to induce hydrophobic collapse. A moderate $\beta$-sheet foldamer ${ }^{2-24}$ made up of three leucine residues was used to provide a handle on the formation of the fibre-like structure. The histidine was placed towards the interior, nonpolar region of the peptide to allow for axial coordination of the water insoluble (DPP)Zn. And the exterior lysines produce a highly positively charged region that when neutralized at high $\mathrm{pH}$, induces $\beta$-sheet formation and fibre formation. The lysine-rich exterior is then capable of mineralizing $\mathrm{TiO}_{2}$ on the assembled peptide's surface yielding the complex hybrid material, Fig. 2. Two peptides c16- $\mathrm{AHL}_{3} \mathrm{~K}_{3}-\mathrm{CO}_{2} \mathrm{H}$ and $\mathrm{cl} 6-\mathrm{AHL}_{3} \mathrm{~K}_{9}-\mathrm{CO}_{2} \mathrm{H}$ were produced to observe the dependence of mineralization on the number of lysine residues present. The peptides were synthesized by standard Fmoc based solid-phase synthesis and purified by reversed phase high-performance liquid chromatography. The identity of the peptides was confirmed by matrix-assisted laser desorption/ionization-mass spectrometry.

Peptide assembly. The self-assembled peptide amphiphile material was generated under slightly altered conditions from our previous report, namely the samples were heated to induce $\beta$ sheet formation. Briefly, a $250 \mu \mathrm{M}$ solution of the peptide amphiphile was made by mixing a portion of a fluid $1 \mathrm{wt} \%$ solution of the peptide into $100 \mathrm{mM}$ ammonium hydroxide, then heated to $65^{\circ} \mathrm{C}$ for $10 \mathrm{~min}$. The peptides self-assemble into nanofibers via neutralization of the lysine residues $(\mathrm{pKa} \sim 10.5)$ which trigger $\beta$-sheet assembly and the propagation of nanofiber formation. c16- $\mathrm{AHL}_{3} \mathrm{~K}_{3}-\mathrm{CO}_{2} \mathrm{H}$ assembles into bundled fibres as previously reported. The unusual circular dichroism spectrum $\lambda_{\min }=229 \mathrm{~nm}$ is red shifted from the $\beta$-sheet signature spectrum $\lambda_{\min }=218 \mathrm{~nm}$ and was previously established to be a result of twisted and/or aggregated bundles of $\beta$-sheet containing nanofibers, see Supplementary Fig. 1 (ref. 15,25,26). This is consistent with the electron microscopy image detailing the very long and

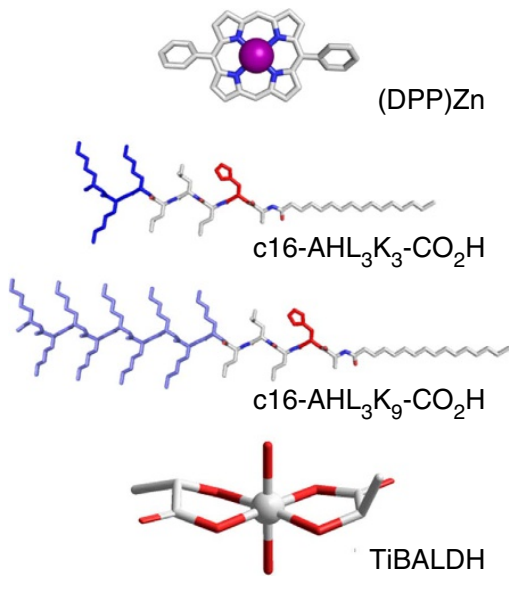

Figure 1 | Precursor molecules for the metalloporphyrin/metal oxide arrays. 

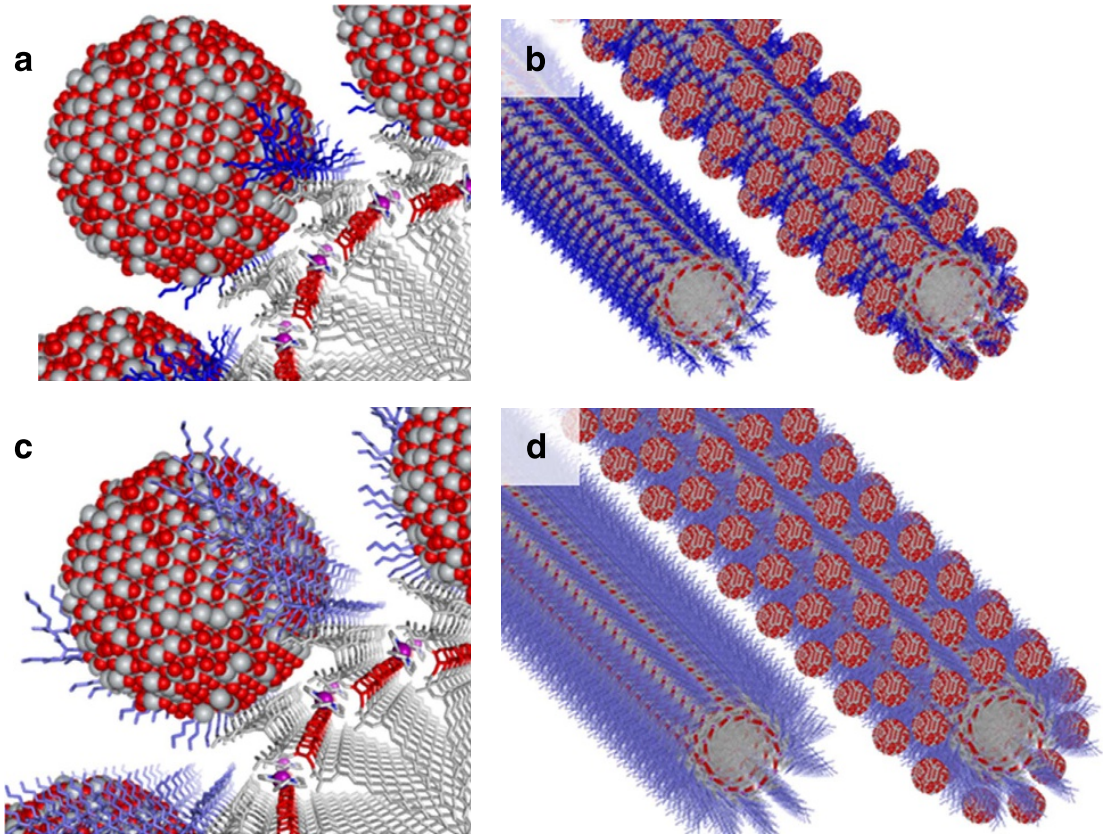

Figure 2 | Self-assembled peptide/(DPP)Zn/ $\mathrm{TiO}_{2}$ arrays. (a) Detail of the interface and (b) cartoon depiction of the self-assembled morphology for c16- $\mathrm{AHL}_{3} \mathrm{~K}_{3}-\mathrm{CO}_{2} \mathrm{H} /(\mathrm{DPP}) \mathrm{Zn} / \mathrm{TiO}_{2}$ and analogous depictions (c,d) for c16- $\mathrm{AHL}_{3} \mathrm{~K}_{9}-\mathrm{CO}_{2} \mathrm{H} /(\mathrm{DPP}) \mathrm{Zn} / \mathrm{TiO}_{2}$

bundled features of the assembled material, see Supplementary Fig. 2. Interestingly, c16- $\mathrm{AHL}_{3} \mathrm{~K}_{9}-\mathrm{CO}_{2} \mathrm{H}$ assembles into lessbundled nanofibers. This is most likely due to the significant increase in lysine residues yielding greater electrostatic repulsion between neighbouring fibres. When $c 16-\mathrm{AHL}_{3} \mathrm{~K}_{9}-\mathrm{CO}_{2} \mathrm{H}$ in $100 \mathrm{mM}$ ammonium hydroxide is heated to $65^{\circ} \mathrm{C}$ and then cooled back to room temperature (RT), $\mathrm{CD}$ yields a spectrum slightly red shifted from a typical $\beta$-sheet spectrum, $\lambda_{\min }=224 \mathrm{~nm}$, see Supplementary Fig. 1 (refs 25,26). Electron microscopy shows nanoscale bundled fibres, see Supplementary Fig. 3. This observation is consistent with the supposition correlating the $\mathrm{CD}$ data with the microscopy data in that the more red-shifted spectra indicate a higher degree to which the fibres are twisted and aggregated. To understand this difference in assembly between the two peptides, thermal assembly studies were executed in which the $\mathrm{n}-\pi^{\star}$ bands of the circular dichroism spectrum were monitored, $\lambda_{\text {mon }}=210$ and $222 \mathrm{~nm}$, while varying the temperature from $10-65^{\circ} \mathrm{C}$, see Supplementary Fig. 1 . The data indicates a greater enthalpic barrier to $\beta$-sheet formation in the case of $\mathrm{cl}-\mathrm{AHL}_{3} \mathrm{~K}_{9}-\mathrm{CO}_{2} \mathrm{H}\left(T_{\mathrm{m}}=48^{\circ} \mathrm{C}\right)$ when compared with c16- $\mathrm{AHL}_{3} \mathrm{~K}_{3}-\mathrm{CO}_{2} \mathrm{H}\left(T_{\mathrm{m}}=28^{\circ} \mathrm{C}\right)$. The presence of the additional lysine residues clearly contributes to this barrier.

Mineralization. Mineralization of inorganic materials by organisms is a natural phenomenon observed in the formation of shells, spines and fibres in protists, diatoms and sponges; and bone in mammals ${ }^{27-29}$. These structures are all induced by peptide sequences with specific characteristics. For example, a high isoelectric point is a common characteristic of peptides and proteins that yield metal-oxides ${ }^{16-20}$. One well-studied example is the water soluble titania precursor, Titanium(IV) bis-ammonium lactato dihydroxy (TiBALDH), which can be converted to $\mathrm{TiO}_{2}$ in the presence of peptides rich in lysine and arginine ${ }^{16-18}$. The mechanism of mineralization is often attributed to an initial electrostatic interaction between the negatively charged titania precursor and the positively charged lysine residues which effectively creates locally concentrated areas of titania. This is followed by dissociation of the lactato ligands and subsequent hydrolysis of the vacant reaction site on the titania ${ }^{30}$. As a result, $\mathrm{TiO}_{2}$ is formed. This observation has yielded a peptide design guideline for interfacing peptides with $\mathrm{TiO}_{2}$ such that peptides exhibiting exposed lysine and/or arginine residues possess the mineralization property. It has also been reported that mineralization of metal oxides on self-assembled peptide surfaces can dictate the morphology of the inorganic material ${ }^{21,31}$. To that effect, the peptides discussed here, c16$\mathrm{AHL}_{3} \mathrm{~K}_{3}-\mathrm{CO}_{2} \mathrm{H}$ and c16- $\mathrm{AHL}_{3} \mathrm{~K}_{9}-\mathrm{CO}_{2} \mathrm{H}$, are excellent candidates for exploring $\mathrm{TiO}_{2}$ mineralization. Two conditions were examined, the disassembled peptide in water and the assembled peptide in ammonium hydroxide solutions. The peptides were diluted from a fluid $1 \mathrm{wt} \%$ stock solution in water to a $500 \mu \mathrm{M}$ solution in water or ammonium hydroxide and heated to $65^{\circ} \mathrm{C}$. After allowing the samples to cool to RT, TiBALDH was added to each sample to achieve a 1 wt $\%(35 \mathrm{mM})$ solution. The unassembled samples immediately became turbid indicative of mineralization, whereas the assembled samples did not show immediate turbidity. All samples were heated to $65^{\circ} \mathrm{C}$ for $10 \mathrm{~min}$ to ensure completion of the mineralization reaction. The samples were washed by pelleting via centrifugation, removal of the supernatant followed by resuspension with the respective solvents three times. Note: control samples were made in the absence of peptide under identical conditions to ensure that $\mathrm{TiO}_{2}$ formation was not a result of thermal degradation.

The morphology of the material was analysed by scanning electron microscopy equipped with a transmission detector. The samples in water exhibited clusters of $\mathrm{TiO}_{2}$ in no discernible assembly, Fig. 3a,d. Samples prepared in ammonium hydroxide exhibited maintenance of the nanofibre structures, but decorated in $\mathrm{TiO}_{2}$ nanoparticles $(<3 \mathrm{~nm})$, Fig. 3 b,e. Particles were specifically observed on the assembled peptide surface. The presence of titania was confirmed via EDX spectroscopy and energy-filtered transmission electron microscopy (EFTEM), see Supplementary Fig. 4. The two peptides were employed under the supposition that $\mathrm{c} 16-\mathrm{AHL}_{3} \mathrm{~K}_{9}-\mathrm{CO}_{2} \mathrm{H}$ would produce either larger particles or more particles than $\mathrm{c} 16-\mathrm{AHL}_{3} \mathrm{~K}_{3}-\mathrm{CO}_{2} \mathrm{H}$. Not only does c16- $\mathrm{AHL}_{3} \mathrm{~K}_{9}-\mathrm{CO}_{2} \mathrm{H}$ have a longer poly-lysine chain, but it also yields extensive individual fibres as observed in the electron 

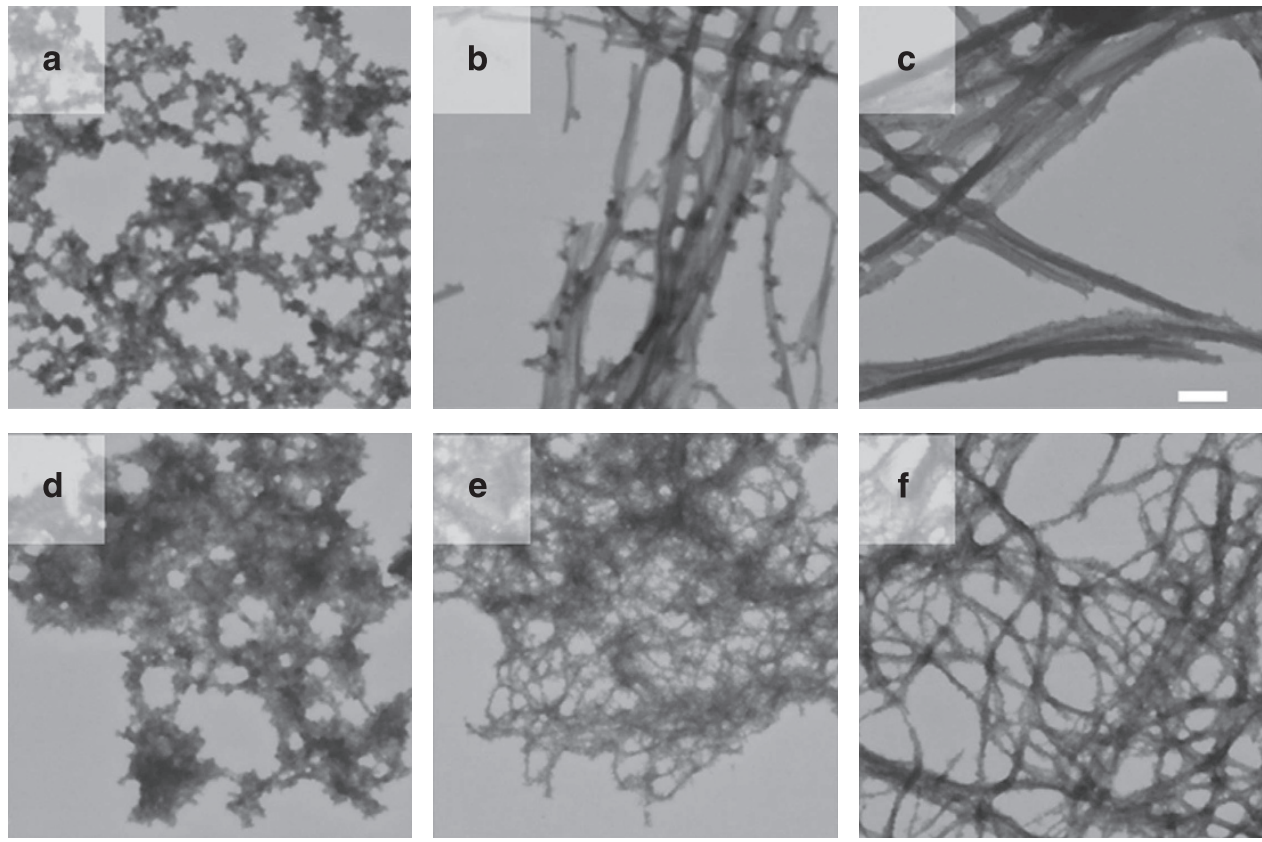

Figure 3 | Mineralization of $\mathrm{TiO}_{\mathbf{2}}$ on unassembled and assembled peptide amphiphiles. Electron micrographs of mineralized $\mathrm{TiO}_{2}$ on $(\mathbf{a})$ unassembled c16- $\mathrm{AHL}_{3} \mathrm{~K}_{3}-\mathrm{CO}_{2} \mathrm{H}$, (b) assembled $\mathrm{c} 16-\mathrm{AHL}_{3} \mathrm{~K}_{3}-\mathrm{CO}_{2} \mathrm{H}$, (c) with (DPP) Zn, (d) unassembled c16- $\mathrm{AHL}_{3} \mathrm{~K}_{9}-\mathrm{CO}_{2} \mathrm{H}$, (e) assembled $\mathrm{c}^{16}-\mathrm{AHL}_{3} \mathrm{~K}_{9}-\mathrm{CO}_{2} \mathrm{H}$ and (f) with (DPP)Zn. Scale bar, $200 \mathrm{~nm}$ for all images.
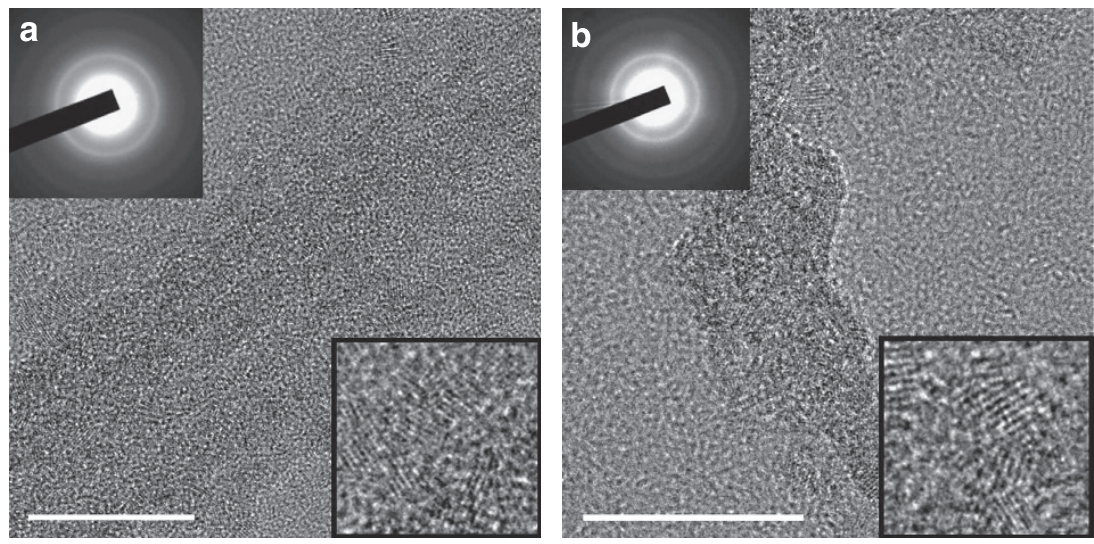

Figure 4 | Evidence of anatase formed at ambient temperatures. HRTEM micrograph of mineralized nanocrystalline $\mathrm{TiO}_{2}$ on the surface of selfassembled peptides (a) $\mathrm{c}_{16}-\mathrm{AHL}_{3} \mathrm{~K}_{3}-\mathrm{CO}_{2} \mathrm{H}$ and (b) $\mathrm{c} 16-\mathrm{AHL}_{3} \mathrm{~K}_{9}-\mathrm{CO}_{2} \mathrm{H}$. Insets: Electron diffraction and magnified view of observed crystal lattices. Scale bar, $20 \mathrm{~nm}$ for both images.

microscopy in the absence of $\mathrm{TiO}_{2}$, see Supplementary Fig. 3 . This provides a greater exposed lysine surface area. By electron microscopy, we find that indeed $\mathrm{c} 16-\mathrm{AHL}_{3} \mathrm{~K}_{9}-\mathrm{CO}_{2} \mathrm{H}$ yields more particles on the peptide surface than $c 16-\mathrm{AHL}_{3} \mathrm{~K}_{3}-\mathrm{CO}_{2} \mathrm{H}$, see Supplementary Fig. 5 (TEM). In the case of c16- $\mathrm{AHL}_{3} \mathrm{~K}_{9}-\mathrm{CO}_{2} \mathrm{H}$, smaller fibres and bundles of fibres were observed suggesting that the addition of TiBALDH does not promote the bundling of fibres. The presence of $\mathrm{TiO}_{2}$ yields a higher contrast producing noticeably different images, see Supplementary Figs 3 and 3e. For c16- $\mathrm{AHL}_{3} \mathrm{~K}_{3}-\mathrm{CO}_{2} \mathrm{H}$, the observed bundling remains in both the presence and absence of $\mathrm{TiO}_{2}$. Although, it appears that the fibres become more rigid and brittle in the presence of $\mathrm{TiO}_{2}$.

By employing high resolution transmission electron microscopy (HRTEM), we were able to determine that the mineralized $\mathrm{TiO}_{2}$ was crystalline, Fig. 4, and indexing of the electron diffraction pattern indicated an anatase crystal phase, see
Supplementary Fig. 6. The quantity of crystalline particles on c16- $\mathrm{AHL}_{3} \mathrm{~K}_{9}-\mathrm{CO}_{2} \mathrm{H}$ exceeds that of $\mathrm{c} 16-\mathrm{AHL}_{3} \mathrm{~K}_{3}-\mathrm{CO}_{2} \mathrm{H}$. One unusual aspect observed in the bundles of fibres of the two peptide assemblies is that $c 16-\mathrm{AHL}_{3} \mathrm{~K}_{3}-\mathrm{CO}_{2} \mathrm{H}$, which features more rigid fibres appeared to organize the particles in between neighbouring bundles yielding some organization to the particles on the fibres whereas c16- $\mathrm{AHL}_{3} \mathrm{~K}_{9}-\mathrm{CO}_{2} \mathrm{H}$ yielded densely packed yet entangled fibres, see Supplementary Fig. 5 (TEM). These two observations provide a potentially useful platform when examining the interplay between self-assembly and particle assembly and its effects on the particles' collective properties.

Quantification of $\mathrm{TiO}_{2}$. While the electron microscopy indicates a greater population of particles on the assembled c16- $\mathrm{AHL}_{3} \mathrm{~K}_{9}$ $\mathrm{CO}_{2} \mathrm{H}$ peptide than the $c 16-\mathrm{AHL}_{3} \mathrm{~K}_{3}-\mathrm{CO}_{2} \mathrm{H}$ peptide, it is of 
interest to quantitatively determine how much of the titanium precursor is consumed by the peptide. This was achieved by a twofold approach, (1) analyse the turbidity of the sample with respect to increasing TiBALDH concentration and (2) use a colorimetric assay in which 3,4 dihydroxybenzoic acid (dhba) is used to coordinate with the remaining TiBALDH in solution generating $\left[\mathrm{Ti}(\mathrm{dhba})_{3}\right]^{2-}, \lambda_{\max }=380 \mathrm{~nm}$ (refs 18,32,33). As discussed, the peptides in water do not assemble into any observable structure. When performing the titrations under unassembled conditions, we found that $\mathrm{c} 16-\mathrm{AHL}_{3} \mathrm{~K}_{3}-\mathrm{CO}_{2} \mathrm{H}$ and c16- $\mathrm{AHL}_{3} \mathrm{~K}_{9}-\mathrm{CO}_{2} \mathrm{H}$ consumed $19 \pm 1$ and $38 \pm 2$ molar equivalents of the TiBALDH precursor respectively, see Supplementary Figs 7,8. This was not surprising due to the simple fact that more lysines are present on the longer peptide. Analysing the peptides under assembled conditions we found that c16- $\mathrm{AHL}_{3} \mathrm{~K}_{9}-\mathrm{CO}_{2} \mathrm{H}$ was found to convert the same molar equivalents of TiBALDH to $\mathrm{TiO}_{2}$ as the unassembled structure, $38 \pm 2$ mol. eq. (see Supplementary Fig. 8), whereas the assembled c16- $\mathrm{AHL}_{3} \mathrm{~K}_{3}-\mathrm{CO}_{2} \mathrm{H}$ was found to consume more than twofold fewer titanium equivalents, $7 \pm 1 \mathrm{~mol}$. eq. (see Supplementary Fig. 7) than the analogous unassembled study. This can be explained by the high degree of bundling in the sample resulting in fewer displayed lysine residues available for mineralization. Consistent with the electron microscopy studies, we find that the unbundled peptide fibres of $\mathrm{c} 16-\mathrm{AHL}_{3} \mathrm{~K}_{9}-\mathrm{CO}_{2} \mathrm{H}$ yield an efficient $\mathrm{TiO}_{2}$ mineralization platform whereas the heavily bundled structure of $\mathrm{c} 16-\mathrm{AHL}_{3} \mathrm{~K}_{3}-\mathrm{CO}_{2} \mathrm{H}$ yields fewer $\mathrm{TiO}_{2}$ nanoparticles due to the loss of exposed lysine. The two materials generated provide an excellent platform for comparing efficient electron transfer between the metalloporphyrin dye and the nanoparticulate semiconducting $\mathrm{TiO}_{2}$.

Dye incorporation. We previously reported the ability to incorporate zinc protoporphyrin IX ((PPIX)Zn) into the assembled peptide amphiphile, c16- $\mathrm{AHL}_{3} \mathrm{~K}_{3}-\mathrm{CO}_{2} \mathrm{H}^{15}$. In the present study, we replaced (PPIX)Zn with (DPP)Zn. (PPIX)Zn was found to be sensitive to room light and would decompose in less than $24 \mathrm{~h}$. With this knowledge, the porphyrin (DPP)Zn replaced the (PPIX)Zn molecule. This non-natural molecule was intentionally chosen because it serves as a basic building block in more complex porphine systems that have a wide array of functionalities and applications such as: nonlinear optics, molecular beacons, biomolecular imaging reagents and lightharvesting antenna $e^{34-39}$.

To incorporate the (DPP)Zn dye molecule, a $125 \mu \mathrm{M}$ peptide solution was aged for $15 \mathrm{~min}$ in $100 \mathrm{mM} \mathrm{NH}_{4} \mathrm{OH}$ at $65^{\circ} \mathrm{C}$ before addition of (DPP)Zn, $25 \mu \mathrm{M}$. Due to the increased hydrophobicity of the (DPP) $\mathrm{Zn}$ in comparison with the (PPIX)Zn molecule, it was necessary to heat the samples to $>80^{\circ} \mathrm{C}$ followed by sonication to achieve successful chromophore incorporation. We verified the presence of the axially coordinated zinc porphyrin complex by ultraviolet (UV)/visible spectroscopy, Fig. 5 . In the absence of peptide following the above sample preparation, (DPP) $\mathrm{Zn}$ in $100 \mathrm{mM} \mathrm{NH} \mathrm{H}_{4} \mathrm{OH}$ yields a very broad spectrum: split B-band $\left(\lambda_{\max }=415,476 \mathrm{~nm}\right)$ and Q-band $\left(\lambda_{\max }=558,590 \mathrm{~nm}\right)$. A broad red-shifted spectrum signifies aggregation ${ }^{40-42}$. (DPP)Zn $(25 \mu \mathrm{M})$ in the presence of the assembled c16- $\mathrm{AHL}_{3} \mathrm{~K}_{3}-\mathrm{CO}_{2} \mathrm{H}$ and c16- $\mathrm{AHL}_{3} \mathrm{~K}_{9}-\mathrm{CO}_{2} \mathrm{H}(125 \mu \mathrm{M})$ in $100 \mathrm{mM} \mathrm{NH} \mathrm{H}_{4} \mathrm{OH}$ yields a sharp spectrum typical of histidyl axial coordination B-band $\left(\lambda_{\max }=426 \mathrm{~nm}\right)$ and Q-bands $\left(\lambda_{\max }=554,592 \mathrm{~nm}\right)$. Circular dichroism spectroscopy confirms the maintenance of the exciton coupling between neighbouring chromophores as shown by the intense Cotton effect $\left(\lambda_{\max }=423 \mathrm{~nm}, \lambda_{\min }=416 \mathrm{~nm}\right)$ similar to our previous report ${ }^{15}$. Furthermore, the maintenance of the supramolecular morphology in the presence of the dye was
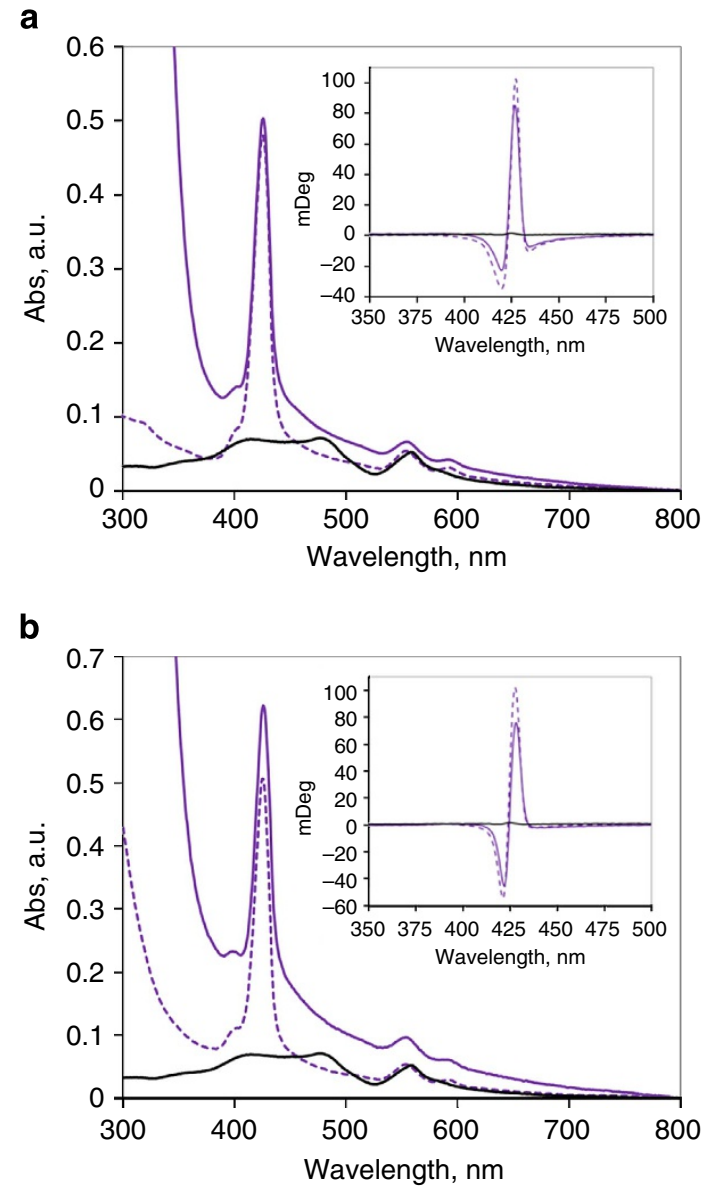

Figure 5 | Incorporation of the dye molecule, (DPP)Zn, into the assembled peptide amphiphile. (a) UV/visible spectra of (DPP)Zn (black line), (DPP) Zn:c16- $\mathrm{AHL}_{3} \mathrm{~K}_{3}-\mathrm{CO}_{2} \mathrm{H}$ (dashed purple line), and (DPP)Zn:c16$\mathrm{AHL}_{3} \mathrm{~K}_{3}-\mathrm{CO}_{2} \mathrm{H}: \mathrm{TiO}_{2}$ (solid purple line). All samples are in $100 \mathrm{mM} \mathrm{NH} \mathrm{H}_{4} \mathrm{OH}$. Inset: Circular dichroism spectra of (DPP)Zn (black line), (DPP)Zn:c16$\mathrm{AHL}_{3} \mathrm{~K}_{3}-\mathrm{CO}_{2} \mathrm{H}$ (dashed purple line) and (DPP) Zn:c16- $\mathrm{AHL}_{3} \mathrm{~K}_{3}-\mathrm{CO}_{2} \mathrm{H}: \mathrm{TiO}_{2}$ (solid purple line). (b) Analagous spectra to a for (DPP) Zn:c16- $\mathrm{AHL}_{3} \mathrm{~K}_{9}-$ $\mathrm{CO}_{2} \mathrm{H}$. Abs, absorbance.

analysed and confirmed to be similar to that found in the absence of (DPP)Zn, see Supplementary Figs 2,3. At this point, TiBALDH was added to the pre-assembled fibres to total $1 \mathrm{wt} \%$ in solution. Mineralization on the surface of the peptide occurred for $10 \mathrm{~min}$ at $65^{\circ} \mathrm{C}$. The sample was pelleted via centrifugation and resuspended in fresh solvent three times to remove excess TiBALDH. We find very little change in the visible spectrum with the exception of a slight increase in baseline absorptivity due to scattering from the increased turbidity of the solution. In the $\mathrm{CD}$ spectrum, this leads to a slight decrease in the intensity. Also, the electron microscopy indicates that the addition of the metalloporphyrin does not disrupt the fibril structure including when $\mathrm{TiO}_{2}$ is mineralized on the peptide surface, Fig. 3c,f. Thus, a platform for charge separation events similar to that of DSCs is generated, in which the orientation and spatial distance between the dye and the inorganic material is well controlled and structurally predictable.

Charge-separated state. The characterized self-assembled hybrid material, c16- $\mathrm{AHL}_{3} \mathrm{~K}_{9}-\mathrm{CO}_{2} \mathrm{H}:(\mathrm{DPP}) \mathrm{Zn}: \mathrm{TiO}_{2}$, yields a platform in which the external semiconducting $\mathrm{TiO}_{2}$ and the internal dye molecule, (DPP)Zn, are separated by a specific distance 
determined by the length of the peptide chain. Here, we presume that the three leucine residues separate the dye molecule, which is axially coordinated to the histidine residue, and the $\mathrm{TiO}_{2}$, which is mineralized by the lysine residues, Fig. 2 . The distance from the histidine to the first lysine residue is $>13 \AA$ along the peptide backbone. To spectroscopically observe a photoinduced chargeseparated state, electron paramagnetic resonance (X-band, 9.4 $\mathrm{GHz}$ ) was employed to observe the characteristic signatures of the electron/hole pair of the zinc porphyrin cation radical and lattice-trapped electrons within $\mathrm{TiO}_{2}$. Three samples were analysed under visible illumination $(\lambda>400 \mathrm{~nm})$ to confirm the charge-separated state: (1) c16- $\mathrm{AHL}_{3} \mathrm{~K}_{9}-\mathrm{CO}_{2} \mathrm{H}: \mathrm{TiO}_{2}$, (2) c16$\mathrm{AHL}_{3} \mathrm{~K}_{9}-\mathrm{CO}_{2} \mathrm{H}:(\mathrm{DPP}) \mathrm{Zn}$ and (3) cl6- $\mathrm{AHL}_{3} \mathrm{~K}_{9}-\mathrm{CO}_{2} \mathrm{H}:(\mathrm{DPP})$ $\mathrm{Zn}: \mathrm{TiO}_{2}$. In sample (1), no signal was observed as expected under visible illumination. However, when illuminating with UV/visible light we observe a signature spectrum for reduced anatase titania ${ }^{43}$ and an oxidized species $(g=2.004)$, presumably a $-\mathrm{CH}$ radical on the peptide as characterized by the presence of a doublet with a $17 \mathrm{G}$ hyperfine coupling, see Supplementary Fig. 9 (ref. 44). The observation of anatase $\mathrm{TiO}_{2}$ confirms our findings in the HRTEM studies (vide infra). In sample (2), we observe a single line at $g=2.004$. Somewhat surprisingly, a triplet species of excited (DPP)Zn is not observed. Our previous report suggests that a triplet species is never formed due to an exciton annihilation mechanism ${ }^{15}$. Here, the observed spectrum is typical of a zinc porphyrin cation radical, but no acceptor moiety is present. It is also possible that charge separation along the axis of the assembled porphyrins is occurring in which a separated cation radical (DPP) $\mathrm{Zn}^{+}$and an anion radical (DPP) $\mathrm{Zn}^{-}$result ${ }^{45}$. Both species have a similar $g$ value of $\sim 2.004$ and vary only in line width, which would yield a spectrum consistent with that observed in sample (2). It is prudent to note that in the absence of the peptide, (DPP)Zn yields a typical triplet spectrum as has been seen in related molecules, see Supplementary Fig. 10 (refs 46,47). Finally, in sample (3) we observe a signal from the cation radical of (DPP)Zn dye $(g=2.003)$ and the signal that corresponds to anatase lattice trapped electrons $\left(g_{\perp}=1.990, g_{\|}^{1}=1.961\right.$ and $\left.g_{\|}^{2}=1.958\right)$ (ref. 43). Figure 6 illustrates the observed phenomenon, in which the dye molecule, excited by visible light, transfers an electron to the nanocrystalline anatase $\mathrm{TiO}_{2}$. Charge recombination was not observed at low temperatures (up to $20 \mathrm{~K}$ ) but upon warming the sample to RT and then cooling back down to $20 \mathrm{~K}$, all signals were absent indicating that complete charge recombination had occurred during the thaw-freeze process.

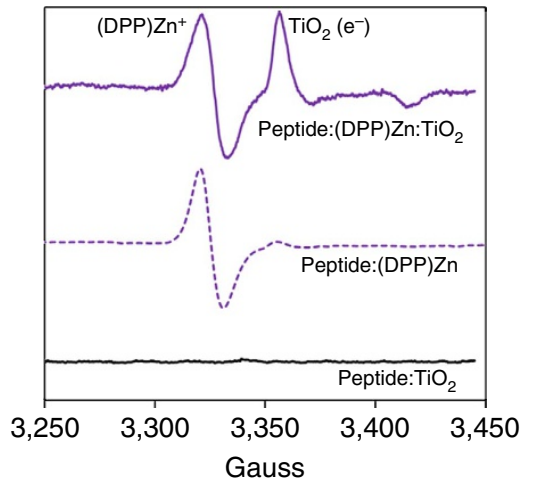

Figure 6 | Charge separation in the hybrid peptide/(DPP)Zn/TiO

structure. X-band EPR spectra of $\mathrm{c} 16-\mathrm{AHL}_{3} \mathrm{~K}_{9}-\mathrm{CO}_{2} \mathrm{H}: \mathrm{TiO}_{2}$ (black line), c16$\mathrm{AHL}_{3} \mathrm{~K}_{9}-\mathrm{CO}_{2} \mathrm{H}:(\mathrm{DPP}) \mathrm{Zn}$ (purple dotted line) and $\mathrm{c} 16-\mathrm{AHL}_{3} \mathrm{~K}_{9}-$

$\mathrm{CO}_{2} \mathrm{H}$ :(DPP) $\mathrm{Zn}: \mathrm{TiO}_{2}$ (purple line) frozen in $100 \mathrm{mM} \mathrm{NH} \mathrm{H}_{4} \mathrm{OH}$ at $10 \mathrm{~K}$ and illuminated with visible light $(>400 \mathrm{~nm})$.
The peptide sequence is also important in tuning the efficient transfer of electrons from the excited (DPP) $\mathrm{Zn}$ molecule to the $\mathrm{TiO}_{2}$ particles. Here, we comparatively analysed the samples c16- $\mathrm{AHL}_{3} \mathrm{~K}_{3}-\mathrm{CO}_{2} \mathrm{H}:(\mathrm{DPP}) \mathrm{Zn}: \mathrm{TiO}_{2}$ and c16- $\mathrm{AHL}_{3} \mathrm{~K}_{9}-\mathrm{CO}_{2} \mathrm{H}$ : (DPP) $\mathrm{Zn}: \mathrm{TiO}_{2}$. We found that more lysine residues result in more $\mathrm{TiO}_{2}$ on the surface of the assembled peptide. When we analyse these two samples by X-band electron paramagnetic resonance (EPR), we find that indeed more lysine amino acids/ more $\mathrm{TiO}_{2}$ results in more electrons injected into $\mathrm{TiO}_{2}$. Specifically, when c16- $\mathrm{AHL}_{3} \mathrm{~K}_{3}-\mathrm{CO}_{2} \mathrm{H}$ :(DPP) $\mathrm{Zn}: \mathrm{TiO}_{2}$ is illuminated with visible light, we see the same signal from the (DPP)Zn cation radical but the signal from the lattice-trapped electrons in $\mathrm{TiO}_{2}$ is significantly diminished when compared with that of c16$\mathrm{AHL}_{3} \mathrm{~K}_{9}-\mathrm{CO}_{2} \mathrm{H}$, see Supplementary Fig. 11. While these results were expected, they highlight the degree to which these materials can be tailored through peptide sequence variation.

\section{Discussion}

In summary, we have developed a new material inspired by the photoinitiated redox pathways in nature in which a peptide amphiphile capable of binding a metalloporphyrin for solar harvesting can also mineralize $\mathrm{TiO}_{2}$ on the surface of the peptide yielding a nanostructured, organic/inorganic hybrid material. We were able to confirm the simple notion that increasing the number of positively charged lysine residues leads to more mineralization of $\mathrm{TiO}_{2}$ on the peptide surface. This could also be explained by the larger exposed surface area in the less-bundled c16- $\mathrm{AHL}_{3} \mathrm{~K}_{9}-\mathrm{CO}_{2} \mathrm{H}$ assembly. Electron microscopy studies show that both peptides are decorated with anatase $\mathrm{TiO}_{2}$ where the metal oxide is specifically associated with the peptide fibres. Furthermore, we successfully mineralized $\mathrm{TiO}_{2}$ on the assembled peptide structure when the dye molecule (DPP)Zn was axially coordinated to an imidazole nitrogen of the histidine residue generating a platform for executing charge separation studies. Upon illumination of this complex hybrid material, electron paramagnetic resonance clearly indicated a charge-separated state between the coordinated (DPP) $\mathrm{Zn}$ and the mineralized $\mathrm{TiO}_{2}$ yielding a (DPP) $\mathrm{Zn}^{+} / \mathrm{TiO}_{2}\left(\mathrm{e}^{-}\right)$hole/electron pair. The degree of charge separation can be modulated through variations in the peptide sequence. In particular, increasing the number of lysine residues that are responsible for mineralization yields more $\mathrm{TiO}_{2}$ and therefore an increased number of charge-separated states. This simple peptide design that affords a complex material will allow us to explore the ability to tune the material through variations in peptide sequence, porphyrin selection, porphyrin position and added redox hopping sites to tune the electron transfer pathway rate and efficiency. The observed charge separation will also allow us to explore the assembly as the fundamental construct of DSCs ${ }^{5,6}$ and photocatalytic watersplitting systems ${ }^{48,49}$.

\section{Methods}

Peptide and porphyrin synthesis. The synthetic procedure for $c 16-\mathrm{AHL}_{3} \mathrm{~K}_{3}$ $\mathrm{CO}_{2} \mathrm{H}$ has been reported in our previous studies. The synthesis of $\mathrm{c} 16-\mathrm{AHL}_{3} \mathrm{~K}_{9}$ $\mathrm{CO}_{2} \mathrm{H}$, cleavage from the resin and purification followed the same strategy as the previously reported peptide with the addition of six lysine residues in the sequence. Matrix-assisted laser desorption/ionization-time of flight mass spectrometry was used to identify the peptide; calculated for $\mathrm{C}_{97} \mathrm{H}_{185} \mathrm{~N}_{25} \mathrm{O}_{16}+\mathrm{H}^{+}, 1957.45 \mathrm{~m} / z$; found, $1957.25 \mathrm{~m} / \mathrm{z}$. The synthetic procedures for (DPP) $\mathrm{Zn}$ are well known following the Lindsey condensation method using trifluoroacetic acid as a catalyst and dichlorodicyanobenzoquinone to complete ring oxidation ${ }^{50}$. The full synthesis of (DPP) $\mathrm{Zn}$ is outlined in Supplementary Fig. 12.

Peptide assembly. Solutions of the peptide amphiphiles $(500 \mu \mathrm{M})$ were made by dilutions from a concentrated stock solution in water (c16- $\mathrm{AHL}_{3} \mathrm{~K}_{3}-\mathrm{CO}_{2} \mathrm{H}, 1 \mathrm{wt} \%$, $8.4 \mathrm{mM}$ or $\mathrm{c} 16-\mathrm{AHL}_{3} \mathrm{~K}_{9}-\mathrm{CO}_{2} \mathrm{H}, 1 \mathrm{wt} \%, 5.1 \mathrm{mM}$ ) with either water (Millipore) or ammonium hydroxide $\left(\mathrm{NH}_{4} \mathrm{OH}, 100 \mathrm{mM}\right)$. The samples were heated to $65^{\circ} \mathrm{C}$ for $15 \mathrm{~min}$ to ensure complete $\beta$-sheet formation and assembly. Thermal folding 
measurements were performed by monitoring the $n-\pi^{*}$ transitions at 210 and $223 \mathrm{~nm}$ of the circular dichroism (JASCO J-815) spectra from $10-65^{\circ} \mathrm{C}$. Spectra were monitored at $20^{\circ} \mathrm{C}$.

Metalloporphyrin binding. To incorporate the metalloporphyrin moiety to the assembled peptide, $1.5 \mu \mathrm{l}$ of a (DPP)Zn stock solution (10 mM in dimethylsulphoxide) was added to a $600 \mu \mathrm{l}$ solution of assembled peptide to yield a $25 \mu \mathrm{M}$ final concentration. Due to the hydrophobic nature of (DPP)Zn, the solution was heated to $>80^{\circ} \mathrm{C}$ for $15 \mathrm{~min}$ and sonicated briefly $(<10 \mathrm{~s})$ before returning to the hot bath. This process is repeated three times. Circular dichroism spectroscopy was used to monitor the exciton coupling intensity to follow the binding event and UV/visible spectroscopy (Cary 50 Spectrophotometer) was used to confirm that the binding event was complete. Upon completion of binding, the sample was cooled to RT and rested for $1 \mathrm{~h}$.

Mineralization studies. TiBALDH (Sigma-Aldrich, $50 \mathrm{wt} \%$ in water) was used as a water soluble precursor to $\mathrm{TiO}_{2}$. The concentration of TiBALDH was varied with respect to peptide concentration to determine how much $\mathrm{TiO}_{2}$ was being formed on the surface of the peptide. We observed $\mathrm{TiO}_{2}$ formation by employing two methods. First, we monitored the turbidity of the solution by UV/visible spectroscopy. Briefly, $300 \mu \mathrm{l}$ of a $500 \mu \mathrm{M}$ solution of the peptide amphiphile (without (DPP) $\mathrm{Zn}$ ) in either water or $100 \mathrm{mM} \mathrm{NH}_{4} \mathrm{OH}$ was placed in a quartz cuvette $(l=1.0 \mathrm{mM})$. From a TiBALDH stock solution in water $(150 \mathrm{mM}) 1.0 \mu \mathrm{l}$ aliquots were added resulting in $0.5 \mathrm{mM}$ addition of TiBALDH added per aliquot. The samples were heated to $65^{\circ} \mathrm{C}$ for $10 \mathrm{~min}$ to ensure reaction completion. A total of $20.0 \mu \mathrm{l}$ of TiBALDH stock solution were added to complete the study. Secondly, a colourimetric assay was employed to support the turbidity data. Similar to the TIRON assay ${ }^{18,32,33}$, we centrifuged the samples to pellet the material. When the clear supernatant containing unreacted TiBALDH is mixed with an excess of dhba (or similar catechol), the molecule $\left[\mathrm{Ti}(\mathrm{dhba})_{3}\right]^{2-}$ results which yields a yelloworange solution, $\lambda_{\max }=380 \mathrm{~nm}\left(\epsilon=3,345 \mathrm{M}^{-1} \mathrm{~cm}^{-1}\right)$. As a result, the amount of consumed TiBALDH precursor can be determined.

When preparing samples for microscopy analysis, $300 \mu \mathrm{l}$ of a $500 \mu \mathrm{M}$ solution of the peptide amphiphile in either water or $100 \mathrm{mM} \mathrm{NH}_{4} \mathrm{OH}$ was placed in an Eppendorf tube. TiBALDH, $6 \mu \mathrm{l}$ of a $50 \mathrm{wt} \%$ stock, was added to the sample resulting in a final $1 \mathrm{wt} \%$ or $35 \mathrm{mM}$ TiBALDH concentration. The sample was incubated at $65^{\circ} \mathrm{C}$ for $10 \mathrm{~min}$. Following incubation, the samples were centrifuged ( $10 \mathrm{~g}$ for $2 \mathrm{~min}$ ) yielding a clear-to-white pellet depending on the peptide. The supernatant was removed via pipetting followed by pellet resuspension with fresh water or $100 \mathrm{mM} \mathrm{NH}_{4} \mathrm{OH}(300 \mu \mathrm{l})$. Sample washing was repeated three times.

Electron microscopy. Seven microlitres of the samples were drop cast onto a 400 mesh copper grid with a carbon or Holey carbon support film (Ted Pella). After $2 \mathrm{~min}$, the excess solution was wicked away and the sample dried under ambient conditions. Analysis of the self-assembled peptide with and without $\mathrm{TiO}_{2}$ mineralized on its surface was analysed by scanning electron microscopy with a transmission detector (JEOL 7500 FE-SEM). Confirmation of successful mineralization of $\mathrm{TiO}_{2}$ was analysed by energy dispersive X-ray spectroscopy. When more detailed analysis of the system was required, the samples were analysed with transmission electron microscopy (JEOL JEM-2010F). HRTEM and EFTEM were used to analyse the crystalline nature of the $\mathrm{TiO}_{2}$ and map out the distribution of the $\mathrm{TiO}_{2}$, respectively. Furthermore, electron diffraction analysis enabled the determination of the crystal phase formed.

Electron paramagnetic resonance. Samples for EPR were concentrated to $2 \mathrm{mM}$ (DPP)Zn and $10 \mathrm{mM}$ Peptide in $100 \mathrm{mM} \mathrm{NH}_{4} \mathrm{OH}$. X-band continuous wave EPR experiments were carried out using a Bruker ELEXSYS E580 spectrometer operating in the X-band $(9.4 \mathrm{GHz})$ and equipped with an Oxford CF935 helium flow cryostat with an ITC-5025 temperature controller. A $300 \mathrm{~W}$ Xe UV lamp (ILC) with $400 \mathrm{~nm}$ cutoff and water as IR filters was used as the light source. The $g$ factors were calibrated for homogeneity and accuracy by comparison with a coal standard, $g=2.00285 \pm 0.00005$. The samples were deaerated, equilibrated in a nitrogen atmosphere for a minimum of $30 \mathrm{~min}$ before EPR measurement.

\section{References}

1. Gray, H. B. \& Winkler, J. R. Long-range electron transfer. Proc. Natl Acad. Sci. USA 102, 3534-3539 (2005).

2. Koepke, J., Hu, X. C., Muenke, C., Schulten, K. \& Michel, H. The crystal structure of the light-harvesting complex II (B800-850) from Rhodospirillum molischianum. Structure 4, 581-597 (1996).

3. Scholes, G. D. \& Fleming, G. R. On the mechanism of light harvesting in photosynthetic purple bacteria: B800 to B850 energy transfer. J. Phys. Chem. B 104, 1854-1868 (2000).

4. Oregan, B. \& Gratzel, M. A low-cost, high-efficiency solar-cell based on dyesensitized colloidal $\mathrm{TiO}_{2}$ films. Nature 353, 737-740 (1991).

5. Grätzel, M. Solar energy conversion by dye-sensitized photovoltaic cells. Inorg. Chem. 44, 6841-6851 (2005).
6. Yella, A. et al. Porphyrin-sensitized solar cells with cobalt (II/III)-based redox electrolyte exceed 12 percent efficiency. Science 334, 629-634 (2011).

7. Sanderson, K. Chemistry: the photon trap. Nature 452, 400-402 (2008)

8. Blankenship, R. E. et al. Comparing photosynthetic and photovoltaic efficiencies and recognizing the potential for improvement. Science 332, 805-809 (2011).

9. Hammarstrom, L., Winkler, J. R., Gray, H. B. \& Styring, S. Shedding light on solar fuel efficiencies. Science 333, 288-288 (2011).

10. Ferreira, K. N., Iverson, T. M., Maghlaoui, K., Barber, J. \& Iwata, S. Architecture of the photosynthetic oxygen-evolving center. Science 303, 1831-1838 (2004).

11. Meyer, G. J. The 2010 millennium technology grand prize: dye-sensitized solar cells. ACS Nano 4, 4337-4343 (2010)

12. Clifford, J. N. et al. Molecular control of recombination dynamics in dye-sensitized nanocrystalline $\mathrm{TiO}_{2}$ films: free energy vs distance dependence. J. Am. Chem. Soc. 126, 5225-5233 (2004).

13. Haque, S. A. et al. Supermolecular control of charge transfer in dye-sensitized nanocrystalline $\mathrm{TiO} 2$ films: towards a quantitative structure-function relationship. Angew. Chem.-Int. Ed. 44, 5740-5744 (2005).

14. Johansson, P. G., Kopecky, A., Galoppini, E. \& Meyer, G. J. Distance dependent electron transfer at $\mathrm{TiO} 2$ interfaces sensitized with phenylene ethynylene bridged RuII-isothiocyanate compounds. J. Am. Chem. Soc. 135, 8331-8341 (2013).

15. Fry, H. C. et al. Self-assembly of highly ordered peptide amphiphile metalloporphyrin arrays. J. Am. Chem. Soc. 134, 14646-14649 (2012).

16. Dickerson, M. B. et al. Identification and design of peptides for the rapid, highyield formation of nanoparticulate $\mathrm{TiO} 2$ from aqueous solutions at room temperature. Chem. Mater. 20, 1578-1584 (2008).

17. Sewell, S. L. \& Wright, D. W. Biomimetic synthesis of titanium dioxide utilizing the R5 peptide derived from Cylindrotheca fusiformis. Chem. Mater. 18, 3108-3113 (2006).

18. Cole, K. E., Ortiz, A. N., Schoonen, M. A. \& Valentine, A. M. Peptide- and long-chain polyamine-induced synthesis of micro- and nanostructured titanium phosphate and protein encapsulation. Chem. Mater. 18, 4592-4599 (2006).

19. Kroger, N. et al. Bioenabled synthesis of rutile (TiO2) at ambient temperature and neutral pH. Angew. Chem.-Int. Ed. 45, 7239-7243 (2006).

20. Cole, K. E. \& Valentine, A. M. Spermidine and spermine catalyze the formation of nanostructured titanium oxide. Biomacromolecules 8, 1641-1647 (2007).

21. Nonoyama, T. et al. $\mathrm{TiO} 2$ synthesis inspired by biomineralization: control of morphology, crystal phase, and light-use efficiency in a single process. J. Am. Chem. Soc. 134, 8841-8847 (2012).

22. Kim, C. W. A. \& Berg, J. M. Thermodynamic beta-sheet propensities measured using a zinc finger host peptide. Nature 362, 267-270 (1993).

23. Minor, D. L. \& Kim, P. S. Measurements of the beta-sheet forming propensities of amino acids. Nature 367, 660-663 (1994).

24. Smith, C. K., Withka, J. M. \& Regan, L. A Thermodunamic scale for the beta-sheet forming tendencies of the amino acids. Biochemistry 33, 5510-5517 (1994).

25. Pashuck, E. T., Cui, H. G. \& Stupp, S. I. Tuning supramolecular rigidity of peptide fibers through molecular structure. J. Am. Chem. Soc. 132, 6041-6046 (2010).

26. Manning, M. C., Illangasekare, M. \& Woody, R. W. Circular-dichroism studies of distorted alpha-helices, twisted beta-sheets, and beta-turns. Biophys. Chem. 31, 77-86 (1988).

27. Chen, C. L. \& Rosi, N. L. Peptide-based methods for the preparation of nanostructured inorganic materials. Angew. Chem.-Int. Ed. 49, 1924-1942 (2010).

28. Sarikaya, M., Tamerler, C., Schwartz, D. T. \& Baneyx, F. O. Materials assembly and formation using engineered polypeptides. Annu. Rev. Mater. Res. 34, 373-408 (2004).

29. Dickerson, M. B., Sandhage, K. H. \& Naik, R. R. Protein- and peptidedirected syntheses of inorganic materials. Chem. Rev. 108, 4935-4978 (2008).

30. Kinsinger, N. M., Wong, A., Li, D. S., Villalobos, F. \& Kisailus, D. Nucleation and crystal growth of nanocrystalline anatase and rutile phase $\mathrm{TiO} 2$ from a water-soluble precursor. Cryst. Growth Design 10, 5254-5261 (2010).

31. Sone, E. D. \& Stupp, S. I. Bioinspired magnetite mineralization of peptideamphiphile nanofibers. Chem. Mater. 23, 2005-2007 (2011).

32. Yoe, J. H. \& Armstrong, A. R. A new colorimetric reagent for titanium. Science 102, 207 (1945).

33. Yoe, J. H. \& Armstrong, A. R. Colorimetric determination of titanium with ... 2-dihydroxbenzene-3, 5-disulfonate. Anal. Chem. 19, 100-102 (1947).

34. Lin, V. S. Y., Dimagno, S. G. \& Therien, M. J. Highly conjugated, acetylenyl bridged porphyrins - new models for light harvesting antenna systems. Science 264, 1105-1111 (1994)

35. LeCours, S. M., Guan, H. W., DiMagno, S. G., Wang, C. H. \& Therien, M. J. Push-pull arylethynyl porphyrins: New chromophores that exhibit large molecular first-order hyperpolarizabilities. J. Am. Chem. Soc. 118, 1497-1503 (1996). 
36. Anderson, H. L. Building molecular wires from the colours of life: conjugated porphyrin oligomers. Chem. Commun. 2323-2330 (1999).

37. Burrell, A. K., Officer, D. L., Plieger, P. G. \& Reid, D. C. W. Synthetic routes to multiporphyrin arrays. Chem. Rev. 101, 2751-2796 (2001).

38. Senge, M. O. et al. Nonlinear optical properties of porphyrins. Adv. Mater. 19, 2737-2774 (2007)

39. Ghoroghchian, P. P. et al. Near-infrared-emissive polymersomes: Selfassembled soft matter for in vivo optical imaging. Proc. Natl Acad. Sci. USA 102, 2922-2927 (2005).

40. Cai, J. et al. Controlled self-assembly and photovoltaic characteristics of porphyrin derivatives on a silicon surface at solid-liquid interfaces. Soft Matter 10, 2612-2618 (2014)

41. Kano, K., Minamizono, H., Kitae, T. \& Negi, S. Self-aggregation of cationic porphyrins in water. Can pi-pi stacking interaction overcome electrostatic repulsive force. J. Phys. Chem. A. 101, 6118-6124 (1997).

42. Hunter, C. A. \& Sanders, J. K. M. The nature of pi-pi interactions. J. Am. Chem. Soc. 112, 5525-5534 (1990)

43. Hurum, D. C., Agrios, A. G., Gray, K. A., Rajh, T. \& Thurnauer, M. C. Explaining the enhanced photocatalytic activity of Degussa P25 mixed-phase $\mathrm{TiO}_{2}$ using EPR. J. Phys. Chem. B 107, 4545-4549 (2003).

44. Hawkins, C. L. \& Davies, M. J. EPR studies on the selectivity of hydroxyl radical attack on amino acids and peptides. J. Chem. Soc. Perkin Trans. 2, 2617-2622 (1998).

45. Melomedov, J., Wunsche von Leupoldt, A., Meister, M., Laquai, F. \& Heinze, K. Porphyrin amino acids-amide coupling, redox and photophysical properties of bis(porphyrin) amides. Dalton Trans. 42, 9727-9739 (2013).

46. Shediac, R. et al. Singlet and triplet excited states of emissive, conjugated bis(porphyrin) compounds probed by optical and EPR spectroscopic methods. J. Am. Chem. Soc. 122, 7017-7033 (2000).

47. Angiolillo, P. J., Lin, V. S. Y., Vanderkooi, J. M. \& Therien, M. J. EPR spectroscopy and photophysics of the lowest photoactivated triplet state of a series of highly conjugated (porphinato)Zn arrays. J. Am. Chem. Soc. 117, 12514-12527 (1995).

48. Gratzel, M. Photoelectrochemical cells. Nature 414, 338-344 (2001).

49. Nam, Y. S. et al. Biologically templated photocatalytic nanostructures for sustained light-driven water oxidation. Nat. Nanotechnol. 5, 340-344 (2010).

50. Lee, C. H. \& Lindsey, J. S. One flask synthesis of mesosubstituted dipyrromethanes and their application in the synthesis of trans-substituted porphyrin building blocks. Tetrahedron 50, 11427-11440 (1994).

\section{Acknowledgements}

This work was performed at the Center for Nanoscale Materials, a U.S. Department of Energy, Office of Science, Office of Basic Energy Sciences User Facility under Contract No. DE-AC02-06CH11357.

\section{Author contributions}

H.C.F. designed, synthesized and characterized the molecules and the supramolecular assembly. Y.L. performed TEM experiments. N.M.D. and T.R. performed EPR experiments. H.C.F and T.R. wrote the manuscript.

\section{Additional information}

Supplementary Information accompanies this paper at http://www.nature.com/ naturecommunications

Competing financial interests: The authors declare no competing financial interests

Reprints and permission information is available online at http://www.nature.com/ reprintsandpermissions/

How to cite this article: Fry, H. C. et al. Photoinitiated charge separation in a hybrid titanium dioxide metalloporphyrin peptide material Nat. Commun. 5:4606 doi: $10.1038 /$ ncomms5606 (2014) 


\section{Corrigendum: Photoinitiated charge separation in a hybrid titanium dioxide metalloporphyrin peptide material}

H. Christopher Fry, Yuzi Liu, Nada M. Dimitrijevic \& Tijana Rajh

Nature Communications 5:4606 doi: 10.1038/ncomms5606 (2014); Published 18 Aug 2014; Updated 2 Feb 2015

The original version of this Article contained an error in the spelling of 'Photoinitiated' in the title of the paper. This has now been corrected in both the PDF and HTML versions of the Article. 